\title{
Can the amnesia of the Earth's continental crust be treated by the resilience of accessory minerals? \\ EMILIE BRUAND
}

Laboratoire Magmas et Volcans

Presenting Author: emilie.bruand@uca.fr

Delineating the evolution of the Earth's dynamics and interactions between its different silicate reservoirs (ocean crust, continental crust, mantle) is key to understanding planetary differentiation and the conditions of surface habitability. Today, plate tectonic processes play a major role in creating and destroying the Earth's crust, and modifying its silicate mantle. Reconstructing its long-term evolution is, however, extremely difficult since the Hadean record is essentially missing and most Archean rocks have experienced reworking and overprinting of their original signatures.

An interesting source of information can be found in robust accessory minerals (e.g. zircon, apatite, monazite, titanite...). They can resist secondary processes and erosion, can be dated and incorporate important trace elements sensitive to magma conditions (temperature, $\mathrm{SiO}_{2}$ content, $\mathrm{fO}_{2}$ ). The properties of these tiny minerals are giving the opportunity to recover informations about igneous and metamorphic rocks at the grain scale using few microns spot sizes. These minerals are particularly interesting for Precambrian terranes that have been affected by secondary processes such as multiple metamorphic events, fluid circulation, alteration or erosion. In this contribution, I will present (i) recent development on our understanding of the chemical behaviour of accessory minerals in different magma types through geological time, (ii) new data on apatite inclusions armoured within zircons on Archean terrane and (iii) will discuss the advantages and limitations of using accessory minerals in Archean terranes. Altogether, these new petro-geochemical tools can help to better reconstruct continental crust through time and can be valuable for future work on provenance studies. 